\title{
Part II: new frontiers in antibacterial drug discovery
}

\author{
"Taken together, this two-part issue covers areas of opportunity \\ in both small and larger molecular systems for possible drug \\ development..."
}

Keywords: antibacterial • antibiotic • drug discovery

This is the second part of a two-part issue 'New Frontiers in Antibacterial Drug Discovery' whose purpose has been to inform and stimulate discussion in an area which has rapidly emerged as one of international importance; the first part was recently published [1]. This second part, while including reports of novel small molecule drugs including polymixins [2] and avibactam [3], also includes reviews of unusual peptides with antibacterial activity [4,5], in addition to novel targets [6], and novel ways of avoiding resistance in known targets [7]. New ways of thinking about the problem, of harnessing porins drug delivery [8], or mining the antibiotic resistome [9], for example, are included. Finally, a transcript of a highly informative session "Ask the Experts: how to curb antibiotic resistance and plug the antibiotics gap?" reports the thinking from key players on this important area [10].

Taken together, this two-part issue covers areas of opportunity in both small and larger molecular systems for possible drug development, along with topics which offer other

\section{References}

1 New frontiers in antibacterial drug discovery. Future Med. Chem. 8(9) (2016).

2 Velkov T, Roberts KD, Thompson PE, Li J. Polymyxins: a new hope in combating Gramnegative superbugs? Future Med. Chem. 8(10), 1017-1025 (2016).

3 Wang DY, Abboud MI, Markoulides MS, Brem J, Schofield CJ. The road to avibactam: the first clinically useful non- $\beta$-lactam working somewhat like a $\beta$-lactam. Future Med. Chem. 8(10) 1063-1084 (2016). possible strategies worthy of more detailed investigation. What is clear, is that while the problem is urgent, but tractable, and that while there are many opportunities for interested scientists across a wide spectrum of expertise to make important contributions, effective interdisciplinary and interinstitutional collaborations will be critical for success. A special thanks goes to all authors for their insights in this special issue, which I hope that it will stimulate wider interest in, and the creation of novel ideas for, the development of next-generation antibiotics and anti-infective strategies which take us well past the 21 st century.

Financial \& competing interests disclosure MG Moloney is a Professor of Chemistry at the University of Oxford. The author has no other relevant affiliations or financial involvement with any organization or entity with a financial interest in or financial conflict with the subject matter or materials discussed in the manuscript apart from those disclosed.

No writing assistance was utilized in the production of this manuscript.

4 Knappe D, Kabankov N, Herth N, Hoffmann $\mathrm{R}$. Insect-derived short proline-rich and murine cathelicidin-related antimicrobial peptides act synergistically on Gram-negative bacteria in vitro. Future Med. Chem. 8(10), 1035-1045 (2016).

5 She F, Oyesiku O, Zhou P, Zhuang S, Koenig DW, Cai J. The development of antimicrobial $\gamma$-AApeptides. Future Med. Chem. 8(10), 1101-1110 (2016).

6 Panda D, Bhattacharya D, Gao QH et al. Identification of agents targeting FtsZ assembly. Future Med. Chem. 8(10), 1111-1132 (2016).
Mark G Moloney

Chemistry Research Laboratory, University of Oxford, 12 Mansfield Road, Oxford, OX1 3TA, USA

mark.moloney@chem.ox.ac.uk 
7 Yuk-Ching Tse-Dinh. Targeting bacterial topoisomerase: how to counter mechanisms of resistance. Future Med. Chem. 8(10), 1085-1100 (2016).

8 Scorciapino MA, D’Agostino T, Acosta-Gutierrez S, Malloci G, Bodrenko I, Ceccarelli M. Exploiting the porin pathway for polar compound delivery into Gram-negative bacteria. Future Med. Chem. 8(10), 1047-1062 (2016).
9 Corona F, Blanco P, Alcalde-Rico M, et al. The analysis of the antibiotic resistome offers new opportunities for therapeutic intervention. Future Med. Chem. 8(10), 1133-1151 (2016).

10 Piddock L, Garneau-Tsodikova S, Garner C. Ask the Experts: how to curb antibiotic resistance and plug the antibiotics gap? Future Med. Chem. 8(10), 1027-1033 (2016). 